\title{
Optimum family size for progeny testing in populations with different strains
}

\author{
SR Miraei Ashtiani *, JW James** \\ University of New South Wales, Department of Wool and Animal Science, \\ PO Box 1, Kensington NSW, 2033 Australia
}

(Received 25 September 1992; accepted 11 March 1993)

Summary - The design of progeny tests to identify the best 1 or 2 sires tested is considered for populations consisting of a large number of genetically different strains, such as the Australian Merino. A fixed number of studs enter sires in the test, for which a fixed number of progeny in total are recorded. Evaluation is by best linear unbiased prediction (BLUP) with strain effects being taken as random. When there is little variation between strains the results are similar to the well-known results of Robertson, but when between-strain variation is high the optimum number of sires to be tested is higher and family sizes are smaller, because information on sires from the same strain provides information on each sire.

progeny testing / family size / variation between strains / Australian Merino / selection

Résumé - Taille optimale de famille pour l'épreuve de descendance dans des populations composées de lignées différentes. La planification des épreuves de descendance pour choisir le meilleur ou les 2 meilleurs pères est étudiée dans le cadre de populations comprenant un grand nombre de lignées génétiquement différentes, comme c'est le cas par exemple pour le Mérinos australien. Un nombre donné de lignées soumettent des pères à l'épreuve de descendance, avec un nombre total fixé de descendants contrôlés. L'évaluation des pères se fait par la meilleure prédiction linéaire sans biais (BLUP) avec des effets lignée considérés comme aléatoires. Quand la variation entre lignées est faible, les résultats sont similaires à ceux bien connus de Robertson, mais quand la variation entre lignées est forte, le nombre optimal de pères à soumettre à l'épreuve de descendance est augmenté et les tailles de famille sont diminuées. La raison en est que l'information sur l'ensemble des pères d'une même souche fournit une information sur chacun des pères de la souche.

épreuve de descendance / taille de famille / variation entre lignées / mérinos australien / sélection

\footnotetext{
* On leave from: Department of Animal Science, College of Agriculture, University of Tehran, Karaj, Iran

** Correspondence and reprints
} 


\section{INTRODUCTION}

Progeny testing of bulls has been very extensively used in dairy cattle breeding for many years, and more recently has been widely used in beef cattle breeding. In contrast, it has been very little used in Australian Merino sheep breeding, though there has been some increase in its application in the last few years. This use has largely been in sire reference schemes, aspects of the design of which were discussed by Miraei Ashtiani and James (1991). In this work attention was concentrated on the design of systems to minimise prediction error variances of differences between estimated breeding values, in a similar way to that of Foulley et al (1983). This is, however, not necessarily the best criterion for design of such schemes.

It was pointed out by Robertson (1957) in the dairy cattle context that, when the aim is to select a fixed number of sires and the total number of progeny available is also fixed, there is an optimum family size which will give the greatest expected response. This optimum is a compromise between greater accuracy of estimated breeding values and greater selection intensity. When there is prior information on breeding values, the optimum structure is altered, as shown by James (1979).

It seems useful to adapt Robertson's approach to the design of Australian Merino sire evaluation, but one feature of this breed needs to be taken into account. Short and Carter (1955) showed that the breed is divided into several strains which are much more differentiated than in most livestock breeds, in which strain formation has usually been slight. Mortimer and Atkins (1989) have recently demonstrated that there are substantial genetic differences between studs within a division of the Merino breed such as the Peppin strain. Thus in considering an optimal design to identify (say) the best 1 or 2 sires from those evaluated, it is necessary to take account of both between strain and within strain variation, where here we use strain to mean any genetically different group, so that different Peppin studs are referred to as strains.

In this paper, a progeny test at a single location is assumed, and rams from a given number of studs are to be evaluated with a view to identifying the best 1 or 2 of those tested. The total number of progeny available is fixed. The problem is to determine how many rams from each strain (stud) should be tested in order that the true breeding values of the 1 or 2 with the best estimated breeding values are as high as possible. It will be assumed that the studs involved in the program may be regarded as a random sample from a large population of such studs, and that sires within strains can be taken as unrelated.

\section{THEORY}

In the progeny testing program there are $s$ sires from each of $b$ strains which are mated to females from a common source, and $n$ progeny from each of the $b s$ sires are recorded, so that the total progeny is $T=b s n$. $T$ and $b$ are regarded as fixed, so that the problem is to find optimum values of $s$ and $n$.

If $Y_{i j k}$ is the record on the $k$ th offspring of the $j$ th sire of the $i$ th strain, our model is:

$$
Y_{i j k}=\mu+B_{i}+S_{i j}+E_{i j k}
$$


where $B_{i}$ is half the deviation of the mean of the $i$ th strain from the population mean breeding value $(B V), S_{i j}$ is half the deviation of the $B V$ of an individual sire from its strain mean, and $E_{i j k}$ is an individual progeny deviation. We assume genetic and environmental variances are the same for all strains, denoting the phenotypic variance as $V_{P}$ and the heritability as $h^{2}$. Then $B_{i} \sim N\left(0, V_{B}\right) ; S_{i j} \sim N\left(0, V_{S}\right)$; $E_{i j k} \sim N\left(0, V_{E}\right)$ where $\sim N(\mu, V)$ means normally distributed with mean $\mu$ and variance $V$. It is assumed twins are rare so that all offspring may be taken to be half sibs. We have:

$$
V_{E}=\left(1-\frac{1}{4} h^{2}\right) V_{P}, V_{S}=1 / 4 h^{2} V_{P} \quad \text { and } \quad V_{B}=f V_{S}
$$

so that $f$ represents the ratio of the between-strains to within-strains genetic variance. We define the ratio $k$ as:

$$
k=V_{E} / V_{S}=\left(4-h^{2}\right) / h^{2} .
$$

The overall $B V$ of a sire is $2 u_{i j}$ where $u_{i j}=B_{i}+S_{i j}$. We want to consider BLUP estimates of $u_{i j}$. These can be obtained in 2 ways. In one approach equation [1] is used as the model, and BLUP of $B_{i}$ and $S_{i j}$ are used to find:

$$
\widehat{u}_{i j}=\widehat{B}_{i}+\widehat{S}_{i j}
$$

This would give a diagonal variance-covariance matrix for the random variables to be estimated by BLUP, but the prediction error variances ( $P E V s)$ would need to be calculated for the $\widehat{u}_{i j}$ from those for $\widehat{B}_{i}$ and $\widehat{S}_{i j}$. In the second approach we rewrite the model as:

$$
Y_{i j k}=\mu+u_{i j}+E_{i j k}
$$

with a pattern of correlations among the $u_{i j}$. We then have:

$\operatorname{var}\left(u_{i j}\right)=V_{B}+V_{S}, \operatorname{cov}\left(u_{i j}, u_{i j^{\prime}}\right)=V_{B}$ and $\operatorname{cov}\left(u_{i j}, u_{i^{\prime} j^{\prime}}\right)=0$. We shall adopt the second approach.

Writing [2] in matrix terms we have:

$$
\mathbf{y}=\mathbf{X} \boldsymbol{\theta}+\mathbf{Z u}+\mathbf{e}
$$

with $\operatorname{var}(\mathbf{u})=\mathbf{G}$ and $\operatorname{var}(\mathbf{e})=\mathbf{I} V_{E}$, where $\mathbf{G}$ is block diagonal, consisting of $b$ blocks, each $s$ by $s$, with $V_{B}+V_{S}$ on the diagonal and $V_{B}$ elsewhere. All other elements of $\mathbf{G}$ are zero. We let $\mathbf{C}_{s}$ be the $s$ by $s$ matrix and then $\mathbf{G}=\mathbf{I}_{b} \otimes \mathbf{C}_{s}$ where $\otimes$ denotes the direct product. Then the Henderson mixed model equations are:

$$
\left[\begin{array}{ll}
\mathbf{X}^{\prime} \mathbf{X} & \mathbf{X}^{\prime} \mathbf{Z} \\
\mathbf{Z}^{\prime} \mathbf{X} & \mathbf{Z}^{\prime} \mathbf{Z}+V_{E} \mathbf{G}^{-1}
\end{array}\right]\left[\begin{array}{l}
\widehat{\boldsymbol{\theta}} \\
\widehat{\mathbf{u}}
\end{array}\right]=\left[\begin{array}{l}
\mathbf{X}^{\prime} \mathbf{y} \\
\mathbf{Z}^{\prime} \mathbf{y}
\end{array}\right]
$$

In these equations $\mathbf{X}^{\prime} \mathbf{X}$ is a scalar, $b s n, \mathbf{X}^{\prime} \mathbf{Z}$ and $\mathbf{Z}^{\prime} \mathbf{X}$ are row and column vectors of length $b s$ with each element equal to $n . \mathbf{Z}^{\prime} \mathbf{Z}$ is a diagonal matrix with each diagonal element being $n$.

$$
\mathbf{C}_{s}=V_{S} \mathbf{I}_{s}+V_{B} \mathbf{J}_{s}
$$


where $\mathbf{I}_{s}$ is an $s$ by $s$ unit matrix and $\mathbf{J}_{s}$ an $s$ by $s$ matrix with all elements unity. Therefore:

$$
\mathbf{G}^{-1}=\mathbf{I}_{b} \otimes \mathbf{C}_{s}^{-1}
$$

and

$$
\mathbf{C}_{s}^{-1}=\left(1 / V_{S}\right) \mathbf{I}_{s}-\left[f /\left\{V_{S}(1+s f)\right\}\right] \mathbf{J}_{s} .
$$

Therefore each block of $\mathbf{Z}^{\prime} \mathbf{Z}+V_{E} \mathbf{G}^{-1}$ has the form:

$$
(n+k) \mathbf{I}_{s}-[f k /(1+s f)] \mathbf{J}_{s} .
$$

Inverting the coefficient matrix in [4], one finds that diagonal terms for the bottom right corner are:

$1 /(n+k)+f k /\{(n+k)[n(1+s f)+k]\}+\left[n(1+s f)^{2}\right] /\{b s k[n(1+s f)+k]\}$.

Let:

$$
\begin{aligned}
\alpha & =1 /(n+k) \\
\beta & =f k /\{(n+k)[n(1+s f)+k]\} \\
\delta & =\left\{n(1+s f)^{2}\right\} / b s k\{n(1+s f)+k\} .
\end{aligned}
$$

Then the $P E V$ for any sire is given by:

$$
P E V=V_{E}(\alpha+\beta+\delta) .
$$

For sires from the same strain the prediction error covariance $(P E C)$ is:

$$
P E C_{W}=V_{E}(\beta+\delta)
$$

while for sires from different strains the $P E C$ is:

Now

$$
P E C_{B}=V_{E} \delta \text {. }
$$

So

$$
\begin{aligned}
\operatorname{var}(\mathbf{u}-\widehat{\mathbf{u}}) & =\mathbf{G}-\operatorname{var}(\widehat{\mathbf{u}}) \\
\operatorname{var}(\widehat{\mathbf{u}}) & =\mathbf{G}-\operatorname{var}(\widehat{\mathbf{u}}-\mathbf{u}) .
\end{aligned}
$$

Thus for a given sire:

$$
\begin{aligned}
\operatorname{var}\left(\widehat{u}_{i j}\right) & =V_{B}+V_{S}-V_{E}(\alpha+\beta+\delta) \\
& =V_{S}[f+1-k(\alpha+\beta+\delta)] .
\end{aligned}
$$

For two sires from the same strain:

$$
\begin{aligned}
\operatorname{cov}\left(\widehat{u}_{i j}, \widehat{u}_{i j^{\prime}}\right) & =V_{B}-V_{E}(\beta+\delta) \\
& =V_{S}[f-k(\beta+\delta)],
\end{aligned}
$$

while for 2 sires from different strains:

$$
\operatorname{cov}\left(\widehat{u}_{i j}, \widehat{u}_{i^{\prime} j^{\prime}}\right)=-V_{E} \delta=-V_{S} k \delta .
$$

The correlation between true and estimated breeding values which measures the accuracy of the design and is referred to as reliability, is given by: 
or:

$$
\begin{aligned}
r_{u \widehat{u}}^{2} & =[\operatorname{cov}(u, \widehat{u})]^{2} /[\operatorname{var}(u) \operatorname{var}(\widehat{u})] \\
& =[\operatorname{var}(\widehat{u})]^{2} /[\operatorname{var}(u) \operatorname{var}(\widehat{u})] \\
& =\operatorname{var}(\widehat{u}) / \operatorname{var}(u) \\
& =[1+f-k(\alpha+\beta+\delta)] /(1+f) \\
r_{u \widehat{u}} & =[1+f-\{k(\alpha+\beta+\delta)\} /(1+f)]^{0.5}
\end{aligned}
$$

The response to selection, $R$, which is the criterion for the optimum number of sires to be tested and thus the size of each sire family, is obtained as:

$$
\begin{aligned}
R & =i r_{u \widehat{u}^{2}} 2\left(V_{B}+V_{S}\right)^{0.5} \\
& =2 i r_{u \widehat{u}_{S}} \sigma_{S}(1+f)^{0.5} \\
& =2 i \sigma_{S}[1+f-k(\alpha+\beta+\delta)]^{0.5} \\
& =i \sigma_{A}[1+f-k(\alpha+\beta+\delta)]^{0.5} .
\end{aligned}
$$

Here $\sigma_{A}$ is the within-strain genetic standard deviation, and $i$ is the standardised selection differential corresponding to the proportion of sires selected.

We also need to consider the intra-class correlation of the estimated $B V \mathrm{~s}$. The analysis of variance involves $\Sigma \Sigma \widehat{u}_{i j}^{2}, \Sigma \widehat{u}_{i .}^{2} / s$ and $\widehat{u}_{. .}^{2} / b s$. Omitting the factor $V_{S}$ we can find:

$$
\begin{aligned}
E\left(\Sigma \Sigma \widehat{u}_{i j}^{2}\right) & =b s[1+f-k(\alpha+\beta+\delta)] \\
E\left(\Sigma \widehat{u}_{i .}^{2} / s\right) & =b[1+s f-k \alpha-k s(\beta+\delta)] \\
E\left(\widehat{u}_{. .}^{2} / b s\right) & =1+s f-k \alpha-k s(\beta+\delta)-s(b-1) k \delta
\end{aligned}
$$

Then:

$$
\begin{aligned}
E(S S W) & =b(s-1)(1-k \alpha) \\
E(S S B) & =(b-1)[1+s f-k(\alpha+s \beta)]
\end{aligned}
$$

which gives us:

$$
\begin{aligned}
E(M S W) & =1-k \alpha \\
E(M S B) & =1-k \alpha+s(f-k \beta)
\end{aligned}
$$

The between strains component is then $(f-k \beta)$.

Thus the intra-class correlation between strains is:

$$
\begin{aligned}
t & =(f-k \beta) /[1-k \alpha+f-k \beta] \\
& =(f-k \beta) /[1+f-k(\alpha+\beta)] .
\end{aligned}
$$

This intra-class correlation is important because the standardised selection differential may be seriously affected when $t$ is large, especially if $b$ is small.

Values of the standardised selection differential were approximated as follows. Burrows (1972) showed that the finite population effect for selecting $S$ animals from $N$ can be approximated in the following way. Let $P=S / N$ and let $i^{*}$ be the standardised selection differential for selecting a fraction $\mathrm{P}$ from an infinite (normal) population. Then:

$$
i(S / N) \approx i^{*}-(1-P) /\left[2 i^{*} P(N+1)\right] .
$$


This assumes the animals are independent, $i e$, all selection criteria are uncorrelated.

The case where the $N$ animals are not independent, but consist of $g$ groups each of size $m$ so that $g m=N$ was dealt with by Hill (1976) and Rawlings (1976). As well as giving an exact treatment, each gave an approximation. We investigated both approximations and found that, although they often agree well, on occasions the Hill formula gave greater selection differentials for selecting two sires than for selecting one. These were conditions outside the range for which Hill suggested his approximation, but as they included conditions we wished to use we decided to use the Rawlings formula rather than that of Hill. If $t^{*}$ is the average correlation among all pairs of animals, the Rawlings formula is:

$$
i\left(S, N, t^{*}\right) \approx i(S / N)\left(1-t^{*}\right)^{0.5}
$$

and on substituting the value of $t^{*}$ we have:

$$
i\left(S, N, t^{*}\right) \approx i(S / N)[1-(m-1) t /(N-1)]^{1 / 2}
$$

To find the optimal structure, a design was evaluated by calculating $R / \sigma_{A}$ using equation [5] for 1 and for 2 sires selected, with $i$ calculated using [6] and [7]. The design giving the highest value was taken as optimal. Results of this approximate calculation were checked using a simulation program with 2000 replications for a given set of parameters.

For each set of simulations, the procedure was as follows. For each strain, a random variable was sampled from the appropriate population. Then for each sire to be tested an appropriate random variable was sampled and another random variable was sampled to provide the progeny mean deviation. The BLUP procedure was then used to get EBVs for all sires, and the known true breeding values for the best 1 or 2 on EBV were used to calculate genetic gains. This was replicated 2000 times, and the mean and SE of the genetic gain were calculated. Standard errors were never more than $2.2 \%$ of the mean gain.

In the case of 1 strain or when the $f$ value is very small, the Robertson (1957) approach would be a suitable solution. If $p$ is the proportion selected, $x$ is the truncation point of the standard normal distribution corresponding to $p$, then the optimal structure should be given by:

$$
T / p k=\left(2 x-i^{*}\right) /\left[2 p\left(i^{*}-x\right)\right]
$$

and when $b=1$ then $T=s n$.

\section{RESULTS}

Calculations were made with the total testing facilities set at $T=300,600$ and 1000 . The number of strains $(b)$ was taken as 3,5 , or $10, h^{2}$ was taken as $0.1,0.3$ or 0.5 , and the $f$ ratio as $0.5,0.1$ or 0.01 . For all 81 combinations the values of $s$ which maximised the expected genetic gain were located by a search process and sire family sizes were obtained from $n=T / b s$. 
The maximum responses for different combinations of the parameters are illustrated in tables I, II and III. These were calculated using the Rawlings approximation.

Table I. Maximum responses to selection for a range of values of $h^{2}, b, s$ and $T$ when $f=0.1$ and 1 or 2 best sire(s) is(are) selected. $t$ is the corresponding intraclass correlation between strains.

\begin{tabular}{|c|c|c|c|c|c|c|c|c|}
\hline \multirow[b]{3}{*}{$h^{2}$} & \multirow[b]{3}{*}{$\mathbf{T}$} & \multirow[b]{3}{*}{ b } & \multicolumn{6}{|c|}{ No selected } \\
\hline & & & \multicolumn{3}{|c|}{1} & \multicolumn{3}{|c|}{2} \\
\hline & & & sb & $\mathrm{R} /\left(\mathrm{V}_{\mathrm{A}}\right)^{1 / 2}$ & $\mathbf{t}$ & $\mathrm{sb}$ & $\mathrm{R} /\left(\mathrm{V}_{\mathrm{A}}\right)^{1 / 2}$ & $\mathrm{t}$ \\
\hline \multirow{9}{*}{0.1} & & 3 & 15 & 0.3169 & 0.1560 & 18 & 0.2766 & 0.1632 \\
\hline & 300 & 5 & 15 & 0.3236 & 0.1511 & 20 & 0.2821 & 0.1759 \\
\hline & & 10 & 10 & 0.3241 & 0.1376 & 20 & 0.2860 & 0.1541 \\
\hline & & 3 & 18 & 0.3877 & 0.1435 & 14 & 0.3449 & 0.1551 \\
\hline & 600 & 5 & 20 & 0.3953 & 0.1434 & 25 & 0.3518 & 0.1511 \\
\hline & & 10 & 20 & 0.4007 & 0.1397 & 20 & 0.3551 & 0.1397 \\
\hline & & 3 & 24 & 0.4412 & 0.1391 & 30 & 0.3975 & 0.1481 \\
\hline & 1000 & 5 & 25 & 0.4496 & 0.1373 & 30 & 0.4053 & 0.1435 \\
\hline & & 10 & 30 & 0.4540 & 0.1391 & 30 & 0.4105 & 0.1391 \\
\hline \multirow{9}{*}{0.3} & & 3 & 24 & 0.7546 & 0.1407 & 30 & 0.6791 & 0.1499 \\
\hline & 300 & 5 & 25 & 0.7690 & 0.1450 & 30 & 0.6924 & 0.1511 \\
\hline & & 10 & 30 & 0.7756 & 0.1404 & 30 & 0.7014 & 0.1404 \\
\hline & & 3 & 36 & 0.8808 & 0.1345 & 42 & 0.8049 & 0.1405 \\
\hline & 600 & 5 & 35 & 0.8966 & 0.1309 & 45 & 0.8200 & 0.1396 \\
\hline & & 10 & 40 & 0.9075 & 0.1318 & 40 & 0.8296 & 0.1318 \\
\hline & & 3 & 51 & 0.9729 & 0.1312 & $57-60^{*}$ & 0.8976 & 0.1375 \\
\hline & 1000 & 5 & 50 & 0.9901 & 0.1283 & 60 & 0.9141 & 0.1345 \\
\hline & & 10 & 50 & 1.0021 & 0.1256 & 60 & 0.9253 & 0.1309 \\
\hline \multirow{9}{*}{0.5} & & 3 & 33 & 1.1074 & 0.1352 & 39 & 1.0093 & 0.1418 \\
\hline & 300 & 5 & 35 & 1.1277 & 0.1343 & 40 & 1.0285 & 0.1390 \\
\hline & & 10 & 30 & 1.1399 & 0.1270 & 40 & 1.0414 & 0.1349 \\
\hline & & 3 & 51 & 1.2689 & 0.1295 & 60 & 1.1719 & 0.1355 \\
\hline & 600 & 5 & 55 & 1.2912 & 0.1298 & 60 & 1.1931 & 0.1328 \\
\hline & & 10 & 50 & 1.3064 & 0.1243 & 60 & 1.2077 & 0.1294 \\
\hline & & 3 & $72-75^{*}$ & 1.3855 & 0.1271 & 84 & 1.2899 & 0.1311 \\
\hline & 1000 & 5 & 75 & 1.4094 & 0.1254 & 85 & 1.3128 & 0.1295 \\
\hline & & 10 & 80 & 1.4259 & 0.1249 & 90 & 1.3285 & 0.1284 \\
\hline
\end{tabular}

* The intraclass correlation corresponds to the higher value. $R$ : maximum response; $h^{2}$ : heritability; $b$ : number of strains; $s$ : number of sires per strain; $T$ : total progeny; $f$ : between-strains/within-strains genetic variance.

In table I the value of $f$ has been taken as 0.1 , so $V_{S}=10 V_{B}$. When the heritability or the total number of progeny increases, with other parameters constant, the response is greater, as it is when selecting the best one rather than 
Table II. Maximum responses to selection for a range of values of $h^{2}, b, s$ and $T$ when $f=0.5$ and 1 or 2 best sire(s) is(are) selected. $t$ is the corresponding intraclass correlation between strains.

\begin{tabular}{|c|c|c|c|c|c|c|c|c|}
\hline \multirow[b]{3}{*}{$h^{2}$} & \multirow[b]{3}{*}{$\mathrm{T}$} & \multirow[b]{3}{*}{ b } & \multicolumn{6}{|c|}{ No selected } \\
\hline & & & \multicolumn{3}{|c|}{1} & \multicolumn{3}{|c|}{2} \\
\hline & & & $\mathrm{sb}$ & $\mathrm{R} /\left(\mathrm{V}_{\mathrm{A}}\right)^{1 / 2}$ & $\mathbf{t}$ & $\mathrm{sb}$ & $\mathrm{R} /\left(\mathrm{V}_{\mathrm{A}}\right)^{1 / 2}$ & $\mathrm{t}$ \\
\hline \multirow{9}{*}{0.1} & \multirow{3}{*}{300} & 3 & 18 & 0.3782 & 0.5532 & $27-30^{*}$ & 0.3376 & 0.6271 \\
\hline & & 5 & 20 & 0.4053 & 0.5447 & 30 & 0.3620 & 0.5980 \\
\hline & & 10 & 20 & 0.4184 & 0.5158 & 20 & 0.3708 & 0.5158 \\
\hline & \multirow{3}{*}{600} & 3 & 27 & 0.4525 & 0.5382 & 36 & 0.4095 & 0.5793 \\
\hline & & 5 & 30 & 0.4860 & 0.5361 & 40 & 0.4414 & 0.5754 \\
\hline & & 10 & 30 & 0.5036 & 0.5117 & 40 & 0.4555 & 0.5447 \\
\hline & \multirow{3}{*}{1000} & 3 & 33 & 0.5077 & 0.5091 & 45 & 0.4636 & 0.5510 \\
\hline & & 5 & $35-40^{*}$ & 0.5457 & 0.5226 & 50 & 0.5004 & 0.5527 \\
\hline & & 10 & 40 & 0.5676 & 0.5033 & 50 & 0.5196 & 0.5297 \\
\hline \multirow{9}{*}{0.3} & \multirow{3}{*}{300} & 3 & 33 & 0.8695 & 0.5148 & $42-45^{*}$ & 0.7932 & 0.5575 \\
\hline & & 5 & 35 & 0.9348 & 0.5110 & 50 & 0.8562 & 0.5586 \\
\hline & & 10 & 30 & 0.9713 & 0.4772 & 50 & 0.8884 & 0.5343 \\
\hline & \multirow{3}{*}{600} & 3 & 48 & 0.9987 & 0.4858 & 60 & 0.9212 & 0.5133 \\
\hline & & 5 & 55 & 1.0729 & 0.4953 & 70 & 0.9934 & 0.5260 \\
\hline & & 10 & 60 & 1.1198 & 0.4927 & 70 & 1.0375 & 0.5110 \\
\hline & \multirow{3}{*}{1000} & 3 & 66 & 1.0927 & 0.4684 & $78-81^{*}$ & 1.0152 & 0.4917 \\
\hline & & 5 & 75 & 1.1722 & 0.4784 & $90-95^{*}$ & 1.0927 & 0.5067 \\
\hline & & 10 & 80 & 1.2261 & 0.4770 & 100 & 1.1443 & 0.5029 \\
\hline \multirow{9}{*}{0.5} & \multirow{3}{*}{300} & 3 & 45 & 1.2590 & 0.4917 & 57 & 1.1590 & 0.5216 \\
\hline & & 5 & 50 & 1.3528 & 0.4971 & 65 & 1.2504 & 0.5307 \\
\hline & & 10 & 50 & 1.4115 & 0.4839 & 70 & 1.3044 & 0.5236 \\
\hline & \multirow{3}{*}{600} & 3 & 69 & 1.4238 & 0.4676 & $81-84^{*}$ & 1.3238 & 0.4898 \\
\hline & & 5 & 80 & 1.5270 & 0.4799 & 95 & 1.4245 & 0.5003 \\
\hline & & 10 & 80 & 1.5974 & 0.4718 & 100 & 1.4920 & 0.4971 \\
\hline & \multirow{3}{*}{1000} & 3 & $93-96^{*}$ & 1.5431 & 0.4515 & 111 & 1.4441 & 0.4663 \\
\hline & & 5 & 110 & 1.6519 & 0.4629 & 130 & 1.5501 & 0.4811 \\
\hline & & 10 & 120 & 1.7297 & 0.4667 & 140 & 1.6254 & 0.4836 \\
\hline
\end{tabular}

* The intraclass correlation corresponds to the higher value.

the best 2 sires tested. Higher $h^{2}$ and $T$ result in a greater number of sires being tested, the greater response coming from higher selection intensity rather than more accurate evaluation. The accuracy of evaluation would be fairly low, with 10 progeny per sire often being close to optimal in many situations. When two sires rather than one are selected, the number to be tested should be somewhat greater, but the ratio of responses for the 2 selection regimes is not very sensitive to differences in other parameters, being typically about 1.1 to 1.15 . The between 
Table III. Maximum responses to selection for a range of values of $h^{2}, b, s$ and $T$ when $f=0.01$ and 1 or 2 best sire(s) is(are) selected. $t$ is the corresponding intraclass correlation between strains.

\begin{tabular}{|c|c|c|c|c|c|c|c|c|}
\hline \multirow[b]{2}{*}{$h^{2}$} & \multirow[b]{2}{*}{$\mathrm{T}$} & \multirow[b]{2}{*}{ b } & \multicolumn{6}{|c|}{ No selected } \\
\hline & & & $\mathrm{sb}$ & $\mathrm{R} /\left(\mathrm{V}_{\mathrm{A}}\right)^{1 / 2}$ & $\mathrm{t}$ & $\mathrm{sb}$ & $\mathrm{R} /\left(\mathrm{V}_{\mathrm{A}}\right)^{1 / 2}$ & $t$ \\
\hline \multirow{3}{*}{0.1} & 300 & $\begin{array}{r}3 \\
5 \\
10\end{array}$ & $\begin{array}{l}15 \\
15 \\
10\end{array}$ & $\begin{array}{l}0.3058 \\
0.3065 \\
0.3033\end{array}$ & $\begin{array}{l}0.0165 \\
0.0165 \\
0.0154\end{array}$ & $\begin{array}{l}18 \\
20 \\
20\end{array}$ & $\begin{array}{l}0.2668 \\
0.2668 \\
0.2627\end{array}$ & $\begin{array}{l}0.0170 \\
0.0171 \\
0.0170\end{array}$ \\
\hline & 600 & $\begin{array}{r}3 \\
5 \\
10\end{array}$ & $\begin{array}{l}18 \\
20 \\
20\end{array}$ & $\begin{array}{l}0.3758 \\
0.3764 \\
0.3770\end{array}$ & $\begin{array}{l}0.0153 \\
0.0155 \\
0.0155\end{array}$ & $\begin{array}{l}24 \\
25 \\
20\end{array}$ & $\begin{array}{l}0.0161 \\
0.0161 \\
0.0155\end{array}$ & $\begin{array}{l}0.0161 \\
0.0161 \\
0.0155\end{array}$ \\
\hline & 1000 & $\begin{array}{r}3 \\
5 \\
10\end{array}$ & $\begin{array}{l}24 \\
25 \\
20\end{array}$ & $\begin{array}{l}0.4287 \\
0.4295 \\
0.4283\end{array}$ & $\begin{array}{l}0.0148 \\
0.0148 \\
0.0142\end{array}$ & $\begin{array}{l}30 \\
30 \\
30\end{array}$ & $\begin{array}{l}0.0154 \\
0.0153 \\
0.0152\end{array}$ & $\begin{array}{l}0.0154 \\
0.0153 \\
0.0152\end{array}$ \\
\hline \multirow{3}{*}{0.3} & 300 & $\begin{array}{r}3 \\
5 \\
10\end{array}$ & $\begin{array}{l}24 \\
25 \\
20\end{array}$ & $\begin{array}{l}0.7330 \\
0.7342 \\
0.7332\end{array}$ & $\begin{array}{l}0.0149 \\
0.1050 \\
0.0143\end{array}$ & $\begin{array}{l}30 \\
30 \\
30\end{array}$ & $\begin{array}{l}0.6586 \\
0.6600 \\
0.6611\end{array}$ & $\begin{array}{l}0.0156 \\
0.0155 \\
0.0154\end{array}$ \\
\hline & 600 & $\begin{array}{r}3 \\
5 \\
10\end{array}$ & $\begin{array}{l}36 \\
35 \\
40\end{array}$ & $\begin{array}{l}0.8579 \\
0.8596 \\
0.8595\end{array}$ & $\begin{array}{l}0.0142 \\
0.0141 \\
0.4144\end{array}$ & $\begin{array}{l}42 \\
40 \\
40\end{array}$ & $\begin{array}{l}0.7831 \\
0.7846 \\
0.7857\end{array}$ & $\begin{array}{l}0.0147 \\
0.0145 \\
0.0144\end{array}$ \\
\hline & 1000 & $\begin{array}{r}3 \\
5 \\
10\end{array}$ & $\begin{array}{l}48 \\
50 \\
50\end{array}$ & $\begin{array}{l}0.9492 \\
0.0509 \\
0.9522\end{array}$ & $\begin{array}{l}0.0137 \\
0.0138 \\
0.0137\end{array}$ & $\begin{array}{l}57 \\
55 \\
60\end{array}$ & $\begin{array}{r}0.8749 \\
0.8765 \\
0.89775\end{array}$ & $\begin{array}{l}0.0142 \\
0.0140 \\
0.0142\end{array}$ \\
\hline \multirow{3}{*}{0.5} & 300 & $\begin{array}{r}3 \\
5 \\
10\end{array}$ & $\begin{array}{l}33 \\
35 \\
30\end{array}$ & $\begin{array}{l}1.0782 \\
1.0798 \\
1.0810\end{array}$ & $\begin{array}{l}0.0143 \\
0.0144 \\
0.0140\end{array}$ & $\begin{array}{l}39 \\
40 \\
40\end{array}$ & $\begin{array}{l}0.9816 \\
0.9834 \\
0.9849\end{array}$ & $\begin{array}{l}0.0148 \\
0.0148 \\
0.0147\end{array}$ \\
\hline & 600 & $\begin{array}{r}3 \\
5 \\
10\end{array}$ & $\begin{array}{l}51 \\
50 \\
50\end{array}$ & $\begin{array}{l}1.2381 \\
1.2404 \\
1.2421\end{array}$ & $\begin{array}{l}0.0138 \\
0.0136 \\
0.0136\end{array}$ & $\begin{array}{l}57 \\
60 \\
60\end{array}$ & $\begin{array}{l}1.1423 \\
1.1444 \\
1.1460\end{array}$ & $\begin{array}{l}0.0141 \\
0.0141 \\
0.0140\end{array}$ \\
\hline & 1000 & $\begin{array}{r}3 \\
5 \\
10\end{array}$ & $\begin{array}{c}60-72^{*} \\
70 \\
70\end{array}$ & $\begin{array}{l}1.3537 \\
1.3561 \\
1.3579\end{array}$ & $\begin{array}{l}0.0134 \\
0.0132 \\
0.0132\end{array}$ & $\begin{array}{l}81 \\
80 \\
80\end{array}$ & $\begin{array}{l}1.2592 \\
1.2615 \\
1.2632\end{array}$ & $\begin{array}{l}0.0134 \\
0.0136 \\
0.0135\end{array}$ \\
\hline
\end{tabular}

* The intraclass correlation corresponds to the higher value.

strain correlation in estimated breeding values is $\approx 50 \%$ greater than the correlation between true breeding values, but is not especially high.

In table II it has been assumed that the variance between strains within the population is half the variance of $\mathrm{BVs}$ between sires within strains. In populations like the Merino there is variation between strains for economically important traits of this order of magnitude (Mortimer and Atkins, 1989). If the results are compared with those in table I it is seen, as expected, that the selection response is greater, and also that, other things being equal, the number of sires tested is somewhat 
greater. The magnitude of change is dependent on several variables, but responses are $20-25 \%$ greater, and the number of sires in the test is $\approx 50 \%$ greater. The differences between selecting 1 or 2 sires are very similar to those when $f=0.1$ for selection response and number of sires tested. The between strain correlations in estimated breeding value are $>3.5$ times those in table I, because of the large change in $V_{B} /\left(V_{B}+V_{S}\right)$.

Table III shows the results of an extreme case, when genetic variance is 100 times greater within than between groups $(f=0.01)$. Consequently, the between strain correlations are very small and, as expected, the results are less dependent on the number of strains involved in the test and are almost uniform for each level of $h^{2}$ and $T$. The effects of $h^{2}$ and $T$ on responses are more or less the same as in tables I and II. Another expectation is that in this case the results should be fairly close to those for an undivided population (Robertson, 1957). We found reasonable agreement between the 2 sets of results. Perfect agreement could not be expected because of differences in calculation procedures, as well as the small differences in underlying assumptions.

The proportion selected in all cases studied was never more than $11 \%$, so selection differentials are reasonably high.

Table IV. The differences between the maximum responses to selection and corresponding number of sires in the test, relative to the case of $b=3$, when sires from 10 strains are involved in the test.

\begin{tabular}{|c|c|c|c|c|c|c|c|c|}
\hline \multirow{2}{*}{\multicolumn{3}{|c|}{ No selected }} & \multicolumn{6}{|c|}{$h^{2}$} \\
\hline & & & \multicolumn{2}{|r|}{0.1} & \multicolumn{2}{|r|}{0.3} & \multicolumn{2}{|r|}{0.5} \\
\hline & \multirow[b]{2}{*}{ f } & \multirow[b]{2}{*}{$\mathrm{T}$} & & & Relativ & changes in: & & \\
\hline & & & $\mathrm{sb}$ & $\mathrm{R} /\left(\mathrm{V}_{\mathrm{A}}\right)^{1 / 2}$ & $\mathrm{sb}$ & $\mathrm{R} /\left(\mathrm{V}_{\mathrm{A}}\right)^{1 / 2}$ & $\mathrm{sb}$ & $\mathrm{R} /\left(\mathrm{V}_{\mathrm{A}}\right)^{1 / 2}$ \\
\hline \multirow[t]{6}{*}{1} & 0.1 & 300 & 0.33 & 0.0227 & 0.25 & 0.0278 & -0.09 & 0.0293 \\
\hline & & 600 & 0.11 & 0.0335 & 0.11 & 0.0303 & -0.02 & 0.0296 \\
\hline & & 1000 & 0.25 & 0.0290 & -0.02 & 0.0300 & 0.07 & 0.0292 \\
\hline & 0.5 & 300 & 0.11 & 0.1062 & -0.09 & 0.1171 & 0.11 & 0.1211 \\
\hline & & 600 & 0.11 & 0.1129 & 0.25 & 0.1213 & 0.15 & 0.1219 \\
\hline & & 100 & 0.21 & 0.1180 & 0.21 & 0.1221 & 0.25 & 0.1209 \\
\hline \multirow[t]{6}{*}{2} & 0.1 & 300 & 0.11 & 0.0340 & 0.00 & 0.0328 & 0.03 & 0.0318 \\
\hline & & 600 & -0.17 & 0.0296 & -0.05 & 0.0307 & 0.00 & 0.0305 \\
\hline & & 1000 & 0.00 & 0.0327 & 0.05 & 0.0309 & 0.07 & 0.0299 \\
\hline & 0.5 & 300 & -0.33 & 0.0983 & 0.11 & 0.1200 & 0.22 & 0.1255 \\
\hline & & 600 & 0.11 & 0.1123 & 0.16 & 0.1262 & 0.19 & 0.1271 \\
\hline & & 1000 & 0.11 & 0.1208 & 0.23 & 0.1272 & 0.26 & 0.1255 \\
\hline
\end{tabular}

A comparison of having 10 versus 3 strains in the test is shown in table IV, where results are presented as the change in response or number of tested sires as a fraction of the value when $b=3$. When $f=0.1$ the extra response from using 10 strains is $\approx 3 \%$, but when $f=0.5$ the extra response is $\approx 12 \%$. The effects of $T$ and $h^{2}$ on these ratios are very small. 
The approximation results were checked by simulation with 2000 replicates per parameter set, for a number of parameter sets. In almost all cases the simulation gave significantly greater responses than the approximation. Figures 1 and 2 show the approximation as well as the simulation results plotted against the number of sires per strain. In figure $1, h^{2}=0.1$ and in figure $2, h^{2}=0.3$. In both figures $T=300$ and different values of $f$ and $b$ were used. Although for a given value of $b$ the simulation results for successive $s$ values show sampling fluctuations, they generally show a fairly flat pattern near the optima. The sampling fluctuations meant that determination of optimal numbers of sires was rather questionable from the simulations, and we preferred to use the approximation despite its apparent bias in estimating response.

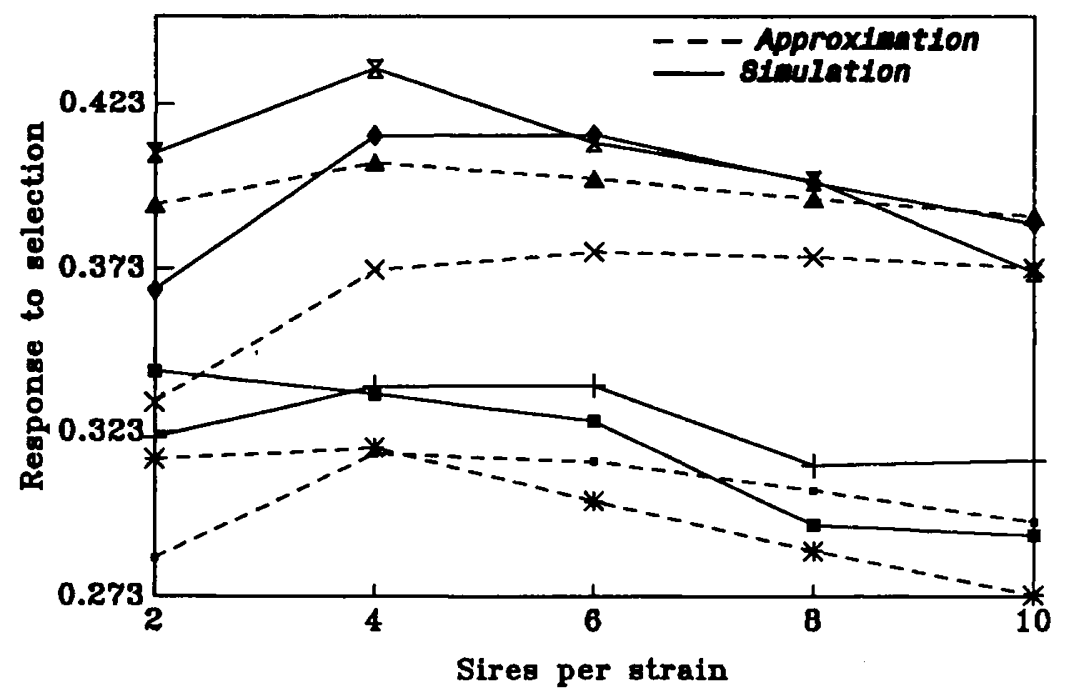

- Approx $f=0.1, b=3+$ simul $l=0.1, b=3$ * $A$ pprox $f=0.1, b=5$ - simul $f=0.1, b=5$

* Approx $l=0.6, b=3 \vdash$ Simul $l=0.6, b=3$ Approx $l=0.6, b=5$ \&imul $l=0.5, b=5$

Fig 1. Comparison of the approximation and the simulation results when $h^{2}=0.1$ and $T=300$. The response is for selection of the best sire out of $s b$ tested.

\section{DISCUSSION}

The results show the effect of genetic variation between strains on the design of progeny testing programs. The calculations were based on the assumption that the number of strains taken from the population is fixed, and equal numbers of candidates from each strain are tested. It is also assumed that the strains may be regarded as a random sample of the population from which they come and that sires are unrelated apart from being members of the same strain.

The assumption that the number of strains is fixed will often be reasonable, since the number of breeders interested in entering sires in the evaluation will determine 


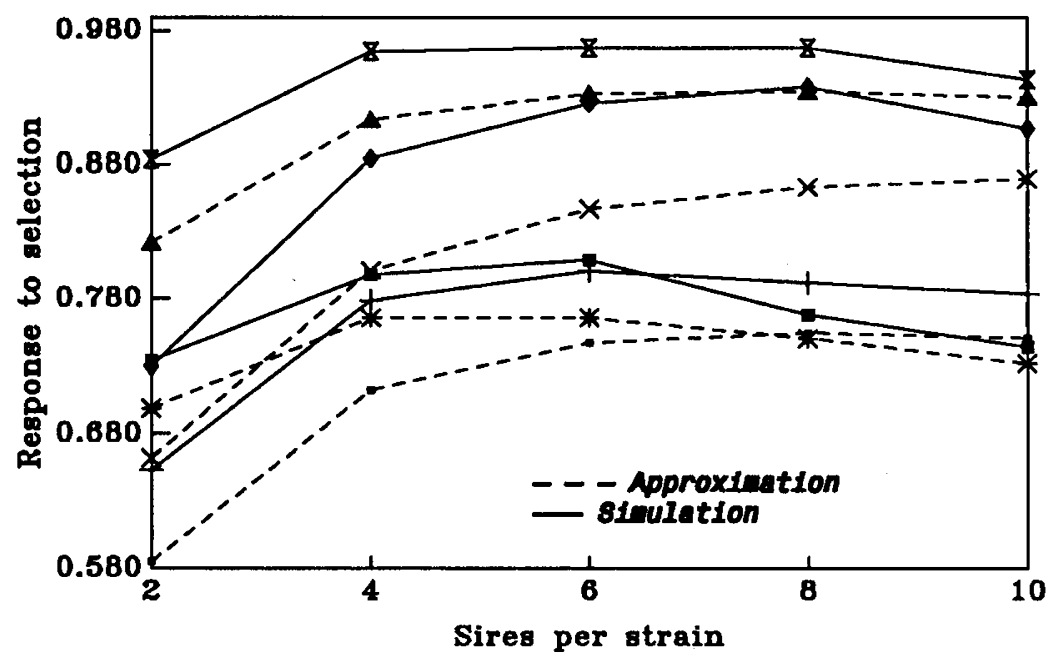

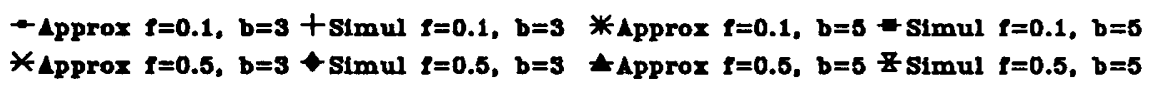

Fig 2. Comparison of the approximation and the simulation results when $h^{2}=0.3$ and $T=300$. The response is for selection of the best sire out of $s b$ tested.

how many strains are available. This is currently the situation in the Australian Merino. However, sometimes the number of strains included should also be regarded as variable, and an optimum for this variable would also be sought. This would significantly increase the amount of computing required, but would not involve any further theoretical developments, and presents an opportunity for extension of these analyses.

The assumptions on relationships among sires are perhaps oversimplified, but are probably not unreasonable for the early stages of such programs. However, once a few highly selected sires were widely used the existing differences among strains would be reduced, and some of the sires from different strains would be related. Thus our conclusions would not be applicable over a long period.

We have assumed that the estimation of breeding values is by BLUP, with random group effects and known parameters. In some cases this led to fairly high correlations between EBVs of sires from the same strain $(0.5-0.6)$. If the group structure were to be ignored, the estimates of breeding value would be less accurate, since they ignore relationships between animals from the same strain. This problem does not arise in the same way in most cattle populations where distinct strains have not formed, and pedigrees can be used to account for genetic similarities between animals. If there are only a few genetic groups, they may be best treated as fixed effects, but in the Australian Merino there are a large number of studs, and it appears reasonable to assume their mean breeding values can be regarded as random effects. The between-strain genetic parameters are, however, poorly known so that our assumption that true values are used in estimation will overestimate the 
gain to be achieved. The difficulties arising from lack of knowledge of between-strain genetic parameters have been discussed in another context by Atkins (1991).

When the between-strain genetic variation was low, our results turned out to be rather similar to those of Robertson (1957). The minor differences probably arise from our use of the finite population selection differential adjusted for correlation between selection criteria on candidates, and from our estimation of the overall mean by BLUP rather than assuming it to be known.

When $b=1$ and sires from only 1 strain are evaluated, results are the same as if there were no variation between strains $(f=0)$. In this case the optimum family size is approximated by $n=0.56\left(K / h^{2}\right)^{0.5}$, where $K$ is the number of progeny tested per sire selected (Robertson, 1957). When there are more strains in the trial and there is appreciable variation between strains, the total number of sires tested increases with the number of strains, and also with $f$. The response to selection also increases. This is attributable to the fact that with a greater number of more variable strains represented there is more variation between tested sires, so that not so many progeny per sire are required to differentiate between them. As a result, more can be tested to allow a greater selection differential to be achieved.

For a given set of conditions, increasing the total number of progeny recorded leads to an increase in both the family size and the number of sires tested.

The comparison of the simulation results and the results of the approximation appears to show a consistent downward bias in the estimates of response given by the approximation, though the location of the optima appears to be little affected. Nevertheless it seems that better approximations for selection differentials than those of Hill (1976) and Rawlings (1976) may be worth searching for. As is not uncommon, the curves of response plotted against number of tested sires are rather flat near the optima, so that precise location of the optimum is not of practical importance, since a value close to the optimum will give a response negligibly less than the best possible.

From a practical viewpoint, the optimum structures seem unlikely to appeal to breeders, because the small family sizes in many cases would be considered too small to give reliable results. The small family sizes are possible because of the use of information on progeny of other sires from the same strain. However, within-strain comparisons will not be very accurate when $f$ is large.

Our results show that selection across strains can give worthwhile improvements over selection within strains, as expected on theoretical grounds. Smith and Banos (1991) have studied this question under different conditions and also found worthwhile advantages for selection across populations in some situations.

\section{ACKNOWLEDGMENTS}

Grateful acknowledgment is made to the Ministry of Culture and Higher Education of the Islamic Republic of Iran for providing a PhD scholarship to the first author, during which this work was conducted. 


\section{REFERENCES}

Atkins K (1992) Data processing and linkages within and between sire evaluation schemes. In: Merino Sire Evaluation in Australia (Brien FD, Kearins RD, Maxwell WMC, eds) Wool Res Dev Corp, Melbourne, Australia, 27-33

Burrows PM (1972) Expected selection differentials for directional selection. Biometrics 28, 1091-1100

Foulley JL, Schaeffer LR, Song H, Wilton JW (1983) Progeny group size in an organised progeny test program of AI beef bulls using reference sires. Can J Anim Sci $63,17-26$

Hill WG (1976) Order statistics of correlated variables and implications in genetic selection programmes. Biometrics 32, 889-902

James JW (1979) Optimum family size in progeny testing when prior information is available. $Z$ Tierz Zuchtungsbiol 95, 194-203

Miraei Ashtiani SR, James JW (1991) Efficient use of link rams in Merino sire reference schemes. Proc Aust Assoc Anim Breed Genet 9, 388-391

Mortimer SI, Atkins K (1989) Genetic evaluation of production traits between and within flocks of Merino Sheep. I. Hogget fleece weight, body weight and wool quality. Aust J Agric Res 40, 433-443

Robertson A (1957) Optimum group size in progeny testing and family selection. Biometrics 13, 442-450

Rawlings JO (1976) Order statistics for a special class of unequally correlated multinormal variates. Biometrics $32,875-887$

Short BF, Carter HB (1955) An Analysis of the Records of the Registered Australian Merino Stud Flocks. CSIRO (Australia), Bull No 276

Smith C, Banos G (1991) Selection within and across populations in livestock improvement. J Anim Sci 69, 2387-2394 